Jurnal Penelitian Pendidikan, Psikologi Dan Kesehatan (J-P3K) 2021, Vol. 2 (No. 1) : 28-38

\title{
Model Creative Art Dalam Konseling Untuk Meningkatkan Quality Of Work Life Dan Coping Stress Pada Karyawan Di Politeknik LP3I Kampus Medan Baru
}

\section{Creative Art Model in Counseling to Improve Quality of Work Life and Coping Stress of Employees at Politeknik LP3I Kampus Medan Baru}

\author{
Abidah Ayu* \\ Manajemen Pendidikan Islam, Sekolah Tinggi Ilmu Tarbiyah Hamzah Fansuri, Indonesia
}

Disubmit: 03 Januari 2021; Diproses: 05 Januari 2021; Diaccept: 16 Maret 2021; Dipublish: 05 April 2021

*Corresponding author: E-mail: abidahayus@gmail.com

\begin{abstract}
Abstrak
Masalah dalam penelitian ini adalah quality of work life dan coping stress pada karyawan di Politeknik LP3I Kampus Medan Baru. Penelitian ini bertujuan mengembangkan model creative art dalam konseling untuk meningkatkan quality of work life dan coping stress pada karyawan di Politeknik LP3I Kampus Medan Baru. Metode yang digunakan adalah penelitian pengembangan (reserch and development) Borg and Gall yang dilaksanakan dengan langkah-langkah penelitian dan pengumpulan data, perencanaan, pengembangan produk, penyempurnaan produk, dan diseminasi. Hasil penelitian menunjukkan model creative art dalam konseling efektif digunakan untuk meningkatkan quality of work life dan coping stress pada karyawan. Nilai $\mathrm{t}=0.04$ dengan $\mathrm{p}<0.05$ setelah diterapkan model creative art dalam konseling untuk meningkatkan quality of work life, artinya terjadi peningkatan quality of work life pada karyawan setelah diterapkan model creative art dalam konseling. Nilai $\mathrm{t}=0.04$ dengan $\mathrm{p}<0.05$ setelah diterapkan model creative art dalam konseling untuk meningkatkan coping stress, artinya terjadi peningkatan coping stress pada karyawan setelah diterapkan model creative art dalam konseling. Penelitian ini menyimpulkan bahwa penggunaan model creative art dalam konseling dapat meningkatkan quality of work life dan coping stress pada karyawan.
\end{abstract}

Kata Kunci : Coping Stress; Model Creative Art, Quality of Work Life

\begin{abstract}
The problem in this study was the quality of work life and coping stress on employees at the Politeknik LP3I Kampus Medan Baru. This study aims to develop a creative art model in counseling to improve quality of work life and coping stress on employees. The method used is Borg and Gall R\&D carried out with research steps and data collection, planning, product development, product improvement, and dissemination. The results showed that creative art models in effective counseling were used to improve the quality of work life and coping stress on employees. Value $t=0.04$ with $p<0.05$ after applying creative art models in counseling to improve quality of work life, meaning that there is an increase for employees after the creative art model is applied in counseling. Value $t=0.04$ with $p<0.05$ after applying creative art models in counseling to increase stress coping, meaning that there is an increase on employees after the creative art model is applied in counseling. This study concludes that the use of creative art models in counseling can improve quality of work life and stress coping on employees.
\end{abstract}

Keywords: Coping Stress; Model Creative Art, Quality of Work Life

DOI: https://doi.orq/10.51849/i-p3k.v2i1.85

Rekomendasi Mensitasi :

Ayu, A. 2021, Model Creative Art Dalam Konseling Untuk Meningkatkan Quality Of Work Life Dan Coping Stress Pada Karyawan di LP3I Kampus Medan Baru. Jurnal Penelitian Pendidikan, Psikologi dan Kesehatan (J-P3K), 2 (1): 28-38. 


\section{PENDAHULUAN}

Kompleksitas pengelolaan sumber daya manusia sangat dipengaruhi oleh banyak faktor. Hal ini sesuai dengan perkembangan dan kemajuan yang berlangsung saat ini. Gusti (2016) mengemukakan, faktor lingkungan, perubahan teknologi yang cepat, kompetisi internasional, dan kondisi perekonomian yang tidak menentu hanyalah beberapa faktor eksternal yang menyebabkan organisasi harus selalu mencari cara-cara baru agar dapat memanfaatkan sumber daya manusia secara lebih efektif. Sedangkan faktor internal, seperti tuntutan dalam memperoleh karyawan yang terlatih.

Karyawan merupakan faktor sentral dalam sebuah organisasi. Untuk itu, karyawan dituntut untuk memiliki keterampilan yang tepat untuk beradaptasi pada perubahan teknologi yang cepat sehingga mampu menyelesaikan pekerjaan secara efektif dan efisien demi kesuksesan kompetitif organisasi. Untuk mewujudkan hal itu, organisasi perlu menciptakan atmosfer yang positif agar karyawan dapat mengaktualisasikan kemampuannya secara maksimal demi tercapainya tujuan organisasi. Lingkungan yang diciptakan oleh organisasi dapat mempengaruhi kinerja karyawan baik langsung maupun tidak langsung, secara fisik maupun nonfisik. Lingkungan yang baik berasal dari konsep yang ditawarkan oleh organisasi.

Cascio (2006) menyatakan bahwa ada dua cara dalam menjelaskan quality of work life, yaitu: Pertama, quality of work life dipandang sebagai sekumpulan persepsi karyawan mengenai rasa aman dalam bekerja, kepuasan kerja dan kondisi untuk dapat tumbuh dan berkembang sebagai manusia. Kedua, quality of work life dipandang sebagai sekumpulan sasaran yang ingin dicapai melalui kebijakan organisasi seperti: kondisi kerja yang aman, keterlibatan kerja, kebijakan pengembangan karir, kompensasi yang adil dan lain-lain. Singkatnya, quality of work life adalah persepsi karyawan akan kesejahteraan mental dan fisik mereka di tempat kerja.

Quality of work life bertujuan untuk meningkatkan kualitas lingkungan organisasi menjadi lebih menyenangkan sehingga karyawan merasa senang karena memiliki pengalaman yang menyenangkan bekerja dan berinteraksi dengan lingkungan kerja (Kondalkar, 2007). Selain itu, tujuan penerapan quality of work life dalam suatu organisasi adalah untuk memenuhi kesejahteraan pada karyawan sehingga bukan hanya bagaimana organisasi dapat menyebabkan karyawannya menjadi lebih baik, tetapi juga dapat berpengaruh terhadap produktivitas, prestasi dan kepuasan karyawan (Hayati, 2013).

Quality of work life meliputi 8 kategori yaitu, komunikasi, partisipasi karyawan, pengembangan karir, penyelesaian konflik, keselamatan dan kesehatan kerja, keamanan kerja, gaji/kompensasi, dan kebanggaan terhadap organisasi (Cascio, 2006). Keuntungan yang didapatkan oleh organisasi yang menyelenggarakan quality of work life secara efektif, yaitu karyawan akan memiliki perasaan memiliki (sense of belonging), perasaan ikut bertanggung jawab (sense of responbility), dan kesediaan berpartisipasi (sense of participation) yang tinggi terhadap 
kegiatan organisasi dan bahkan pada keseluruhan organisasinya. Sederhananya, quality of work life yang diselenggarakan secara efektif akan menciptakan dan mengembangkan loyalitas dan dedikasi yang tinggi pada organisasi dan bahkan pada para pemimpin organisasi (Tjahyanti, 2013).

Fenomena perkembangan kualitas karyawan saat ini menunjukkan belum semua mengadaptasi quality of work life dengan baik. Salah satu organisasi yang mengalami kemunduran karyawan akibat rendahnya quality of work life adalah Politeknik LP3I Kampus Medan Baru. Organisasi yang bergerak pada bidang pendidikan dan pelayanan ini merupakan kampus yang diresmikan pada 18 September 2017 setelah pindah dari bangunan sebelumnya yaitu di Jl. Gajah Mada, Medan.

Hasil wawancara dengan HRD (Human Resource Development) Politeknik LP3I Kampus Medan Baru pada awal Maret 2018 menunjukkan sebagian besar karyawan memiliki kualitas kerja yang rendah. Kehadiran karyawan hanya berkisar pada 60-70 \%. Pembangunan dan perkembangan organisasi tergolong lambat karena kurangnya keterlibatan dan partisipasi karyawan dalam kegiatan organisasi. Beberapa karyawan memilih untuk tidak mengungkapkan masalah yang menghambat pekerjaan mereka. Akibatnya, para karyawan kesulitan menyelesaikan pekerjaan mereka dengan tepat waktu.

Ditemukan juga karyawan yang mengalami masalah komunikasi, ditunjukkan dengan hubungan yang kurang harmonis antar karyawan. Ditemukan juga karyawan yang menolak untuk dipromosikan. Inisitif untuk menawarkan diri mengikuti pelatihan atau seminar tergolong pasif. Sebagian besar karyawan mengeluh karena gaji diberikan jauh dari tanggal seharusnya.

Fenomena kemunduran quality of work life pada karyawan ini menunjukkan kecenderungan memberi dampak negatif pada perkembangan organisasi juga individu karyawan. Pada organisasi, menyebabkan organisasi akan kesulitan dalam mempertahankan karyawan sehingga mengakibatkan tingginya turnover (Wenda, 2015). Pada karyawan, kemunduran produktivitas kinerja dan motivasi karyawan (Wirawan, 2016).

Pada karyawan yang mengalami kemunduran quality of work life ditemukan pula karyawan yang mengalami kesulitan menyelesaikan masalah, mengambil keputusan dan mudah tersinggung (Munandar, 2014). Karyawan ini mengalami kelelahan kerja, sehingga berkurang performa kerjanya, mudah merasa khawatir, muncul stres yang berakibat pada penurunan kinerja hingga berujung pada keputusan meninggalkan pekerjaan. Indikasi ini menunjukkan bahwa karyawan bukan hanya mengalami kemunduran quality of work life tetapi juga memiliki hambatan dalam mengatasi stres kerja.

Stres kerja merupakan faktor-faktor lingkungan kerja yang negatif didalam lingkungan organisasi diantaranya, waktu kerja yang berlebihan, tanggung jawab kerja (Smith dalam Wijono, 2010), hubungan yang tidak baik dengan pihak manajemen atau antar karyawan (Heiriegel dan Slocum dalam Wijono, 2010) sehingga menimbulkan gangguan fungsi mental dan fisik seseorang (Beehr 
dan Newman dalam Wijono, 2010). Keadaan ini mengakibatkan berkurangnya performa kinerja karyawan (Wartono, 2017), motivasi karyawan (Goodson dalam Wijono, 2010), dan kepuasan kerja dan produktivitas kerja (Heiriegel dan Slocum dalam Wijono, 2010).

Stres dalam bekerja dapat dihadapi tanpa memperoleh dampak yang negatif. Usaha yang dapat dilakukan sebagai pertahanan menghadapi stres adalah coping stress. Coping stress merupakan proses individu mencoba untuk mengelola jarak yang ada antara tuntutan-tuntutan, baik itu tuntutan yang berasal dari individu maupun yang berasal dari lingkungan dengan sumber-sumber daya yang mereka gunakan dalam menghadapi stres (Lazarus dan Folkman dalam Smet 1994). Dengan kata lain, coping stress adalah proses yang dilalui oleh individu dalam menyelesaikan keadaan yang menyebabkan stres sebagai respon terhadap situasi yang mengancam dirinya baik secara fisik maupun psikologi (Rasmun, 2004).

Carver, Dkk (Rubbyana, 2012) membagi coping dalam dua dimensi, yakni adaptif dan maladatif. Coping adaptif berarti menangani atau mengatasi stressor secara efektif dan positif. Sedangkan coping maladatif kebalikan dari coping adaptif, yaitu mengatasi stressor secara negatif (Tan dalam (Rubbyana, 2012)). Selanjutnya, Carver mengkategorikan coping meliputi beberapa aspek, yaitu keaktifan diri, membuat perencanaan strategi untuk bertindak mengatasi stres, kontrol diri, mencari dukungan sosial baik secara instrumental maupun emosional, penerimaan, yaitu sikap yang menerima keadaan yang penuh dengan stres sehingga mengaharuskan untuk mengatasi hal tersebut dan religius (Carver et al., 1989).

Teori coping stress Lazarus dan Folkman menjelaskan coping merupakan bentuk usaha-usaha individu baik secara kognitif maupun perilaku untuk mengatasi, mengurangi atau mentolelir tuntutantuntutan internal maupun eksternal yang disebabkan oleh hubungan antara individu dengan peristiwa-peristiwa yang dinilai menimbulkan stres (dalam Amiruddin dan Ambarini, 2014). Karyawan yang memiliki tingkat kemampuan coping yang baik akan memiliki komitmen dan kontrol diri yang tinggi (Amiruddin dan Ambarini, 2014), tidak mudah tersinggung dan khawatir serta bisa mengambil keputusan dengan cepat (Munandar, 2014) sehingga menampilkan performa kinerja yang baik.

Jika dihubungkan fenomena adanya kemunduran quality of work life pada karyawan dan hambatan mengatasi stres maka ada dugaan bahwa kedua hal ini saling berkaitan satu sama lain. Dugaan ini dibenarkan oleh Tsai (dalam Muh. Saleh, 2018, Mosadeghrad, Ferlie, \& Rosenberg, 2011) yang mengemukakan tingkat quality of work life meningkat seiring dengan turunnya kadar stres pada karyawan. Artinya, karyawan yang memiliki quality of work life yang tinggi memiliki kemampuan coping stress yang baik.

Berbagai hal dapat menjadi faktor penyebab rendahnya quality of work life pada karyawan. Tetapi pemicu yang paling sering mengakibatkan karyawan kehilangan performa kerjanya adalah stres kerja. Oleh sebab itu, organisasi dan karyawan secara personal harus memelihara quality of work life untuk meminimalisir stres ditempat kerja (Harsono, 2005). Setidaknya, dengan 
menerapkan quality of work life karyawan memiliki kemampuan coping sebagai mekanisme pertahanan yang mereka lakukan terhadap stres yang mereka alami. Dengan demikian, quality of work life dapat menciptakan kesejahteraan pada karyawan sehingga memiliki kemampuan untuk meminimalisir stres (Schular dalam Badriyah, 2015, Hasibuan, 2013).

Namun hasil penelusuran lebih lanjut melalui observasi yang dilakukan pada 28 Mei hingga 4 Juli 2018 menunjukkan bahwa sebagian besar karyawan terlihat santai dengan pekerjaannya, sedangkan beberapa yang lain sibuk menyelesaikan pekerjaan mereka. Adapula yang ditemukan lebih banyak menghabiskan waktu dengan termenung di depan komputer.

Ketika ditanyai langsung kepada

HRD (Human Resource Development) Politeknik LP3I Kampus Medan Baru diketahui informasi bahwa beberapa karyawan memiliki lebih dari dua tanggung jawab yang harus diselesaikan dengan tingkat prioritas yang hampir sama. Ditemukan pula karyawan yang enggan untuk meminta bantuan kepada karyawan lain yang memiliki waktu senggang. Akibatnya, karyawan mengalami stress kerja dan kemunduran pada kesehatan fisik. Seperti ditemukan karyawan yang sering mengeluh sakit kepala, mudah tersinggung dan memiliki tempramen yang tinggi.

Sebagian karyawan mengeluh atas beban kerja yang begitu banyak, jam masuk kerja yang terlalu cepat berdampak pada banyak ditemukan karyawan yang datang terlambat ke kantor. Ditemukan juga karyawan yang acuh dan mendiamkan orang lain, menutup diri yang berakibat hubungan interpersonal antar karyawan tidak harmonis. Padahal untuk mengurangi stres dibutuhkan dukungan sosial dari lingkungan sekitar.

Ditemukan juga karyawan yang mengeluh atas manajemen waktu yang berubah-ubah dari organisasi sehingga merubah jadwal kerja menjadi padat dan terburu-buru. Terdapat karyawan yang diketahui menyelesaikan konflik kerja secara personal, bahkan ada pula yang langsung menuju kepada Kepala Kampus tanpa diketahui oleh HRD (Human Resource Development). Akibatnya banyak terjadi kesenjangan-kesenjangan baik pihak manajemen dengan karyawan ataupun karyawan dengan karyawan lainnya.

Hasil penelitian menunjukkan penanganan stres dapat dilakukan dengan menggunakan terapi tawa (Anggun dan Harlina, 2012), dukungan sosial (Dodiansyah, 2014), menerapkan prinsip homeostatis (Musradinur,2016), mengelola stres melalui iklim organisasi (Milfa dan Harun, 2012) dan konseling spiritual (Rosmalina, 2017).

Penelitian yang lain menunjukkan quality of work life (kualitas kehidupan kerja) pada karyawan dapat ditingkatkan dengan menggunakan goal setting counseling (Paramita dan Fahmie, 2014), meningkatkan komitmen organisasi (Ramadhoan,2015), pembinaan dan pemberdayaan sumber daya manusia (Kambey dan Suharnomo, 2013, Belferik dan Milfa, 2013), Coaching dan Counseling (Sulastiana, dkk, 2017, Misriah,2013).

Fenomena tentang rendahnya quality of work life dan kemampuan coping stress pada karyawan menunjukkan bahwa model konvensional tidak sepenuhnya 
dapat menstimulasi individu karyawan. Model konvensional yang diterapkan pada karyawan selama ini terkesan cenderung monoton dan menggunakan media terbatas. Jarang sekali di organisasi menggunakan media kreatif seperti lukisan, gambar, musik dan media kreatif lainnya untuk menstimulasi perkembangan quality of work life dan coping stress pada karyawan.

Beberapa karyawan mendapatkan pengaruh positif terhadap model konvensional yang diterapkan. Namun, banyak pula yang mengalami perubahan yang tidak maksimal. Oleh sebab itu, dibutuhkan model baru yang memiliki inovasi dapat mengintegrasikan segala aspek yang ada pada manusia sehingga mampu memaksimalkan kompetensi menjadi karyawan yang berkualitas dan memiliki pertahanan yang kuat terhadap stres secara sistemik dan menyeluruh.

Penelitian menunjukkan konseling dengan menggunakan creative art $\mathrm{di}$ organisasi dapat meningkatkan kesadaran, kemampuan komunikasi dan kompetensi, menciptakan hubungan yang baik dengan orang lain, memiliki kemampuan menganalisis dan memecahkan masalah (Liebman dalam Akila dan Nandagopal, 2015). Penelitian lain menunjukkan, penggunaan konseling dengan creative art terbukti dapat mengentaskan masalah kecemasan pada orang dewasa (Milfa, 2016), meningkatkan kemampuan untuk berpikir kreatif (Usman, 2014), membantu mencapai pertumbuhan pribadi (Alhadi dan Eka, 2017) dan membantu menurunkan tingkat traumatis yang dialami orang dewasa (Schouten dalam Alhadi dan Eka, 2017, Foa, Keane dan Friedman, 2009). Sejalan dengan penelitian-penelitian ini, konseling kreatif yang memanfaatkan seni ekspresif dapat meningkatkan keberhasilan mengentaskan permasalahan konseli (Dunphy, Mullane dan Jacobson, 2013).

Model konseling creative art belum populer bagi konselor dan pihak manajemen organisasi di Politeknik LP3I Kampus Medan Baru, sehingga belum lazim menggunakannya. Selain sumber pengetahuan yang terbatas, HRD (Human Resource Development) dan pihak manajerial juga banyak yang sudah nyaman dengan model konvensional yang selama ini mereka gunakan.

Namun, ketika fenomena adanya kemunduran quality of work life dan kemampuan coping stress pada karyawan ditemukan, maka penting untuk menyiapkan suatu model konseling creative art. Kebutuhan meningkatkan quality of work life dan coping stress pada karyawan, maka digunakan beberapa media kreatif sebagai media yang digunakan dalam proses konseling. Seperti lukisan, gambar, musik, pasir, dan berbagai media kreatif lainnya. Tujuannya agar karyawan bisa menampilkan dan mengekspresikan diri sehingga mampu meningkatkan kesadaran dan kompetensi diri melalui integrasi perkembangan kognitif, sosial, emosional, fisik, psikologi, dan perilaku.(Gladding dalam Malchiodi, 2003; Gladding,2011).

\section{HASIL DAN PEMBAHASAN}

Berdasarkan hasil uji coba yang dilakukan pada kelompok eksperimen pada 3 orang karyawan untuk menentukan seberapa besar keefektifan buku panduan model creative art dalam konseling untuk meningkatkan quality of work life dan 
coping stress pada karyawan berdasarkan pretest dan postest yang dilakukan. Perolehan hasil pretest dan postest pada 3 orang karyawan dapat dilihat pada gambar dibawah ini:

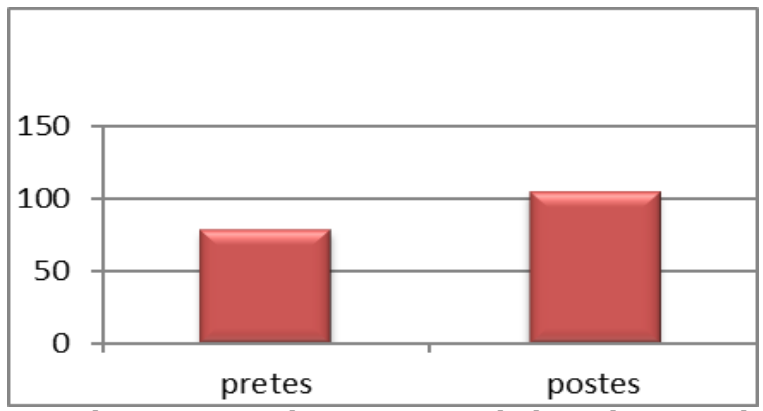

Gambar 1. Peningkatan QWL sebelum dan sesudah perlakuan pada kelompok eksperimen

Pada gambar di atas menunjukkan perbedaan peningkatan quality of work life secara umum sebelum dan sesudah diberikan perlakuan. Sebelum diberikan perlakuan secara umum peningkatan quality of work life berada pada rata-rata 78. Penilaian tersebut berada pada kategori belum optimal (Rendah) berdasarkan skala. Namun setelah diberikan perlakukan dengan menerapkan buku panduan layanan konseling model creative art peningkatan quality of work life secara umum berada pada rata-rata 104. Penilaian ini berada pada kategori meningkat sesuai harapan (sangat tinggi) dengan kenaikan sebesar 26 atau sebesar $33 \%$.

Sedangkan peningkatan coping stress digambarkan sebagai berikut:

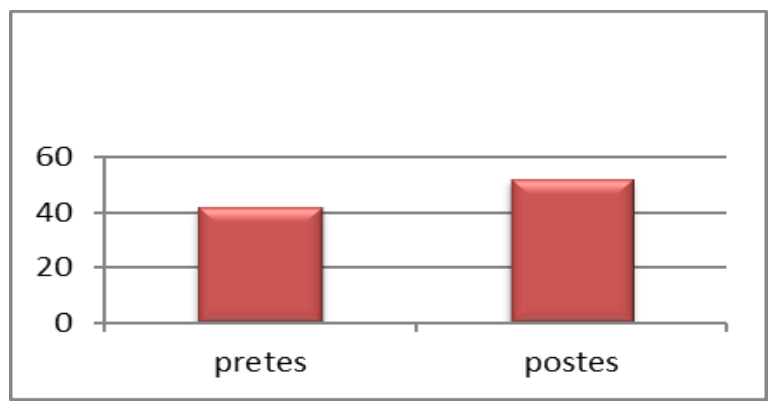

Gambar 2. Peningkatan CP sebelum dan sesudah perlakuan pada kelompok eksperimen
Secara umum berdasarkan tabel di atas peningkatan coping stress sebelum diberikan perlakuan berada pada rata-rata 43. Penilaian tersebut berada pada kategori belum meningkat (Rendah) berdasarkan skala. Sedangkan setelah diberi perlakuan, coping stress menjadi meningkat dengan rata-rata 52. Penilaian ini berada pada kategori meningkat sesuai harapan (sangat tinggi) dengan selisih skor sebesar 9 atau sama dengan $20 \%$ pada nilai persentase.

Model creative art untuk meningkatkan quality of work life dan coping stress pada karyawan diberikan sebanyak 5 kali pertemuan. Pada 3 karyawan di Politeknik LP3I mengalami peningkatan quality of work life dan coping stress setelah diberi perlakuan model creative art dalam konseling. Perolehan hasil pretest dan postest pada 3 orang karyawan di Politeknik LP3I berdasarkan aspek dijelaskan sebagai berikut :

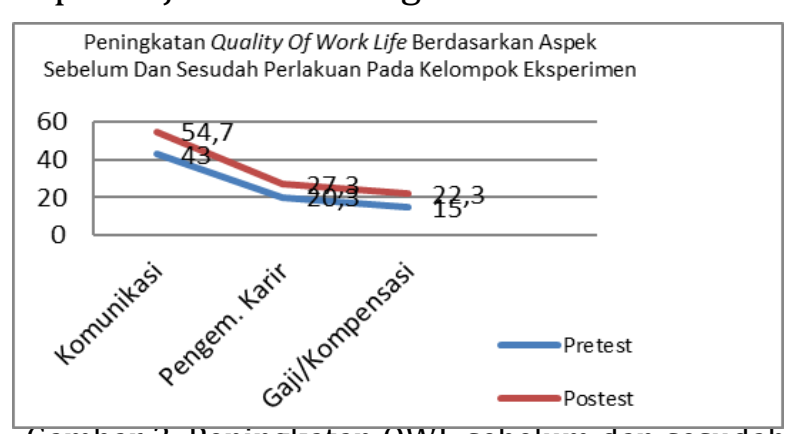

Gambar 3. Peningkatan QWL sebelum dan sesudah perlakuan berdasarkan Aspeknya

Dari gambar di atas (Gambar 3) dapat diketahui bahwa peningkatan paling signifikan terlihat pada aspek komunikasi, awalnya berada pada nilai rata-rata 43 setelah diterapkan buku panduan layanan konseling model creative art meningkat menjadi 54,7 dengan selisish skor 11,7 atau sama dengan 27\%. Aspek pengembangan karir meningkatkan dari 
nilai rata-rata 20,3 menjadi 27,3 dengan selisih skor sebesae 7 atau sama dengan $34 \%$ dan aspek gaji / kompensasi meningkat dari nilai rata-rata 15 menjadi 22,3 dengan selisih skor sebesar 7,3 atau sama dengan 49\%. Penilaian ini berdasarkan hasil skala quality of work life.

Sedangkan peningkatan pada coping stress pada karyawan dapat dilihat sebagai berikut:

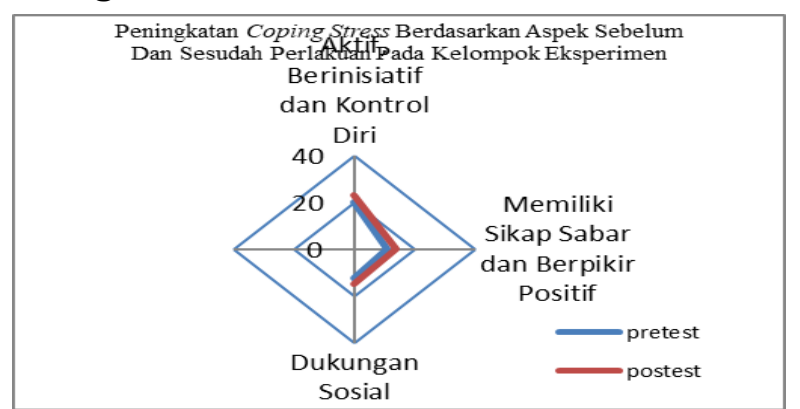

Gambar 4. Peningkatan CS sebelum dan sesudah perlakuan berdasarkan Aspeknya

Dari gambar di atas (Gambar 4) diketahui bahwa peningkatan paling siginifikan pada aspek coping stress adalah keaktifan diri dengan indikator aktif, berinisiatif dan kontrol diri kenaikan sebesar 3 dengan nilai rata-rata dari angka 20 meningkat menjadi 23 dengan selisih persentase sebesar $15 \%$ dan memiliki sikap sabar dan berpikir positif kenaikannya sama dengan indikator aktif, berinisiatif dan kontrol diri. Penilaiannya meningkat dari nilai rata-rata 11 ke 14 dengan selisih angka sebesar 3 atau sama dengan 27\%. Sedangkan pada aspek dukungan sosial baik secara instrumental dan emosional meningkat sebesar 2,7 dengan nilai rata-rata 12,3 meningkat menjadi 15 atau sama dengan persentase sebesar $22 \%$.

Pengembangan buku panduan layanan konseling model creative art dalam penelitian ini sudah dikembangkan dan sudah dinilai untuk meningkatkan quality of work life dan coping stress melalui uji coba. Pengembangan konseling dalam model creative art ini disusun dalam bentuk buku panduan konseling yang dapat dijadikan pedoman dalam pelaksanaan konseling di lingkungan organisasi/perusahaan.

Model konseling untuk meningkatkan quality of work life dan coping stress ini disusun dalam bentuk proyek yang dapat dilaksanakan pada karyawan sebanyak lima sesi. Pada tahap uji coba baik terhadap desain maupun tahap pengembangannya menghasilkan buku panduan layanan konseling model creative art. Dari hasil analisis terhadap kesesuaian, buku ini dinilai layak untuk digunakan sebagai buku pedoman konseling.

Pengembangan buku panduan konseling dalam model creative art untuk membantu meningkatkan quality of work life dan coping stress ini dilakukan dengan lima sesi kegiatan konseling. Pada sesi pertama karyawan diajak untuk melakukan visualisasi kreatif. Kegiatan konseling dimulai dengan konselor membacakan instruksi dimana karyawan berimajinasi tentang instruksi yang diberikan. Selanjutnya karyawan diminta untuk menggambarkan apa yang ia lihat selama kegiatan visualisasi kreatif pada selembar kertas HVS. Setelah digambarkan karyawan akan diminta untuk menceritakan gambar yang telah dibuat. Kegiatan ini diselingi dengan berlatih kemampuan karyawan untuk mengaktualisasikan kemampuan komunikasinya dengan menggunakan kartu bergambar dan figurin. 
Pada kegiatan konseling pertemuan kedua, karyawan diajak untuk menggambarkan simbol yang mengacu kepada dirinya, harapan karir dan hambatam-hambatan untuk menuju harapan tersebut. Hal ini bertujuan agar karyawan menyadari dan menetapkan karirnya. Kemudian dilanjutkan dengan bermain kartu yang mengarah pada keadaannya di tempat kerja, bertujuan untuk mengetahui keadaannya dan tindakan yang diambil apabila berada pada kondisi tersebut.

Kegiatan konseling pertemuan ketiga, karyawan diajak bermain plastisin, membuat beraneka ragam bentuk sehingga karyawan mengetahui bagaimana kondisinya ketika di tempat kerja. Kemudian karyawan diajak bermain alat musik dengan menggunakan topeng. Melalui permainan peran karyawan menyadari bahwa dalam kehidupan sehari-hari ditempat kerja berpikir positif dan tetap bersyukur adalah kunci untuk dapat menyelesaikan pekerjaan dengan baik dan mensyukuri gajinya.

Kegiatan konseling pertemuan keempat, karyawan diajak bermain clay dengan mata tertutup dan dengan mata terbuka. Hal ini bertujuan untuk menciptakan daya aktif, berinisiatif dan kontrol diri karyawan dalam mengatasi stress di tempat kerja. Selanjutnya, karyawan diajak untuk menceritakan bentuk yang dibuat sebelumnya untuk mengetahui kondisi karyawan serta mengoptimalkan kemampuan kontrol diri karyawan.

Pada pertemuan terakhir karyawan diajak untuk bermain peran dengan menggunakan figurin. Hal ini dilakukan untuk mengetahui kondisi karyawan di lingkungan keluarga dan rekan kerjanya. Selanjutnya karyawan diajak untuk menceritakan orang-orang yang berada di lingkungan keluarga dan tempat kerja serta peran mereka terhadap diri karyawan.

Berdasarkan uji coba tahap I dan uji coba utama (uji coba tahap II), dapat diketahui bahwa buku panduan layanan konseling creative art untuk meningkatkan quality of work life dan coping stress sesuai dengan apa yang dikemukakan oleh Malchiodi (2003:ix) bahwa aktivitas seni dan kreatif juga telah digunakan sebagai media karena melayani konseling dengan 'bahasa' yang lain tetapi juga karena memiliki kemampuan membantu orang dari segala usia untuk mengeksplorasi emosi dan keyakinan, mengurangi stres, menyelesaikan masalah dan konflik, dan meningkatkan rasa kesejahteraan mereka.

Hasil analisis terhadap penggunaan buku panduan layanan konseling dalam model creative art untuk peningkatan quality of work life ditujukan untuk meningkatkan kemampuan komunikasi, pengembangan karir, memiliki rasa kepuasan dan syukur atas gaji/kompensasi yang diterima dari tempat kerja. Komunikasi, dapat ditingkatkan melalui visualisasi kreatif, menggambar, menceritakan, bermain kartu dan bermain peran dengan figurin. Pengembangan karir, memiliki rasa percaya diri terhadap dirinya sendiri untuk mampu mengemban tanggung jawab atau suatu jabatan, memiliki harapan karir dapat ditingkatkan dengan menggambar harapan karir dan hambatan apa saja yang mengahalangi menuju harapan tersebut. Memiliki rasa puas atas gaji/kompensasi, memiliki rasa 
syukur diilakukan dengan bermain alat musik dan topeng.

Sedangkan hasil analisis terhadap penggunaan buku panduan layanan konseling dalam model creative art untuk membantu meningkatkan coping stress ditujukan agar karyawan mampu mengatasi stres yang menimpa mereka ditempat kerja dengan cara yang positif baik secara kognitif dan perilaku ditunjukkan dengan memiliki keaktifan, inisiatif diri dan kontrol diri untuk mengatasi stress serta menyadari bahwa kehidupan bekerja tidak lepas dengan adanya dukungan sosial dari orang-orang sekitar baik secara instrumental maupun emosional. Keaktifan diri mampu ditingkatkan melalui bermain plastisin dan clay, menulis puisi, sedangkan dukungan sosial ditingkatkan melalui bermain peran dengan figurin.

Dari hasil penelitian ini dapat diketahui bahwa pengembangan buku panduan layanan konseling dalam model creative art menunjukkan peningkatan.

\section{SIMPULAN}

Berdasarkan hasil analisis dan pembahasan dalam penelitian ini, dapat disimpulkan bahwa penerapan buku panduan layanan konseling dengan model creative art untuk meningkatkan quality of work life dan coping stress pada karyawan dapat diterima sehingga dapat menjadi buku pedoman untuk meningkatkan quality of work life dan coping stress pada karyawan.

\section{DAFTAR PUSTAKA}

Alhadi, Said dan W.N Eka Saputra, Integrasi Seni Kreatif Dalam Konseling Dengan Pemanfaatan Seni Visual, Jurnal Fokus
Konseling , Volume 3, No. 2 (2017), Universitas Ahmad Dahlan

Akila L K, dan Choodamani Nandagopal, An Introduction To Art Therapy And Creativity In Organisations, Proceedings Of The International Symposium On Emerging Trends In Social Science Research. Chennai-India, 3-5 April 2015

Amiruddin, Jemmi Halil dan Tri Kurniati Ambarini, Pengaruh Hardiness dan Coping Stress Terhadap Tingkat Stres pada Kadet Akademi TNI-AL. Jurnal Psikologi Industri dan Organisasi. Vol. o3 No. 02, Agustus 2014. Fakultas Psikologi Universitas Airlangga

Badriyah, Mila. 2015. Manajemen Sumber Daya Manusia. Bandung: Pustaka Setia

C.O, Wenda, Pengaruh Quality Of Work Life Terhadap Komitmen Organisasional Karyawan Di CV Sinar Plasindo, AGORA, Vol. 3, Nomor 2, 2015

Carver, C.S., M.F. Scheier, J.K. Weintraub, Assessing Coping Strategies: A Theoretically Based Approach, Journal of Personality and Social Psychology, 1989, Vol. 56, No. 2, by the American Psychological Association

Cascio, W.F. 2006. Managing Human Resources : Productivity, Quality Of Work. Life, Profit. Ed 6. Mcgraw-Hill

Foa, E. B., Keane, T. M., Friedman, M. J., \& Cohen, J. A. (2009). Effective treatments for PTSD. Practice guidelines from the International Society for Traumatic Stress Studies. New York: The Guilford Press

Gladding, Samuel T, 1992. Counseling As An Art: The Creative Arts In Counseling. Alexandria : American Association For Counseling And Development

Hayati, I,K, Analisis Penerapan Quality Of Work Life (Qwl) Terhadap Kepuasan Kerja Dan Komitmen Karyawan Manajemen Industri Akademi Telekomunikasi Bogor, Semnas Fekon: Optimisme Ekonomi Indonesia 2013

Kokndalkar, V.G., 2007. Organizational Behaviour. New Delhi: New Age International Publishers

Munandar, Ashar Sunyoto, 2014. Psikologi Industri dan Organisasi. Jakarta: UI-Press

Manullang Belferik dan Sri Milfayetty, Human Resources Management Based on the Teacher's Empowering. 2012. International Conference on Information Technology and 
Management Science (ICITMS 2012) Proceedings. Springer, Berlin, Heidelberg

Milfayetty, Sri dan Harun Sitompul, Pengaruh Iklim Organisasi, Kemampuan Mengelola Stres Dan Motivasi Berprestasi Terhadap Kinerja Guru: Studi Empiris Di Sub Rayon SMPN 18 Medan. 2012. UNIMED Digital Repository

Milfayetty, Sri. 2016. Creative Art Play dalam Menurunkan Tingkat Kecemasan. Playscope

Misriah, R. Ariyani S. Peran Konseling Dalam Meningkatkan Kinerja Karyawan. Jurnal Ekonomi. Vol. 1 No. 3 Mei - Agustus 2013. UNTAG Cirebon

Malchiodi, Cathy A, 2007. The Art Therapy Sourcebook. Mc Graw-Hill , 2003. Handbook Of Art Therapy. Edited By Cathy A Malchiodi. New York : The Guilford Press

Purnaya, I Gusti Ketut. 2016. Manajemen Sumber Daya Manusia. Yogyakarta: Andi

Paramita, Nidya dan Arief Fahmie, The Impact Of Goal-Setting Counseling To Improve Employee's Motivation, Jurnal Intervensi Psikologi, Vol 6 No. 1, Juni 2014

Refiza, 2016. Pengaruh Quality Of Work Life Terhadap Semangat Kerja, Industrial Engineering Journal Vol.5 No.2

Rasmun, 2004. Stress Koping Dan Adaptasi. Jakarta : CV. Sagung Seto.

Rubbyana, U. (2012). Hubungan antara Strategi Koping dengan Kualitas Hidup pada Penderita Skizofrenia Remisi Simptom. 1(o2), 59-66.

Smith, Allison L., Assessing Creative Approaches In Beginning Counselors: Building The Foundation. 2011.

Wartono, T. (2017). Pengaruh Stres Kerja Terhadap Kinerja Karyawan: Studi Kasus pada Tenaga. 4(1), 221-228.

Wirawan, I. K. O. (2016). Pengaruh quality of work life ( Qwl ) terhadap motivasi kerja pegawai pramu bakti Universitas Pendidikan Ganesha. Jurnal Pendidikan Ekonomi Undiksha, 6(1), 1-10. 